\title{
Implementasi Fuzzy Tsukamoto Dalam Menentukan Upah Gaji Karyawan Perbulan
}

\author{
Siti Maysaroh Saragih ${ }^{1}$, Ayu Lestari ${ }^{2}$, Mahadir Soleh Hutasuhut ${ }^{3}$ \\ ${ }^{1,2,3}$ Mahasiswa STIKOM Tunas Bangsa, Pematangsiantar - Indonesia \\ Jln. Sudirman Blok A No. 1-3 Pematangsiantar, Sumatera Utara \\ Imaysarohsaragih2808@gmail.com, ${ }^{2}$ ayulestari3400@gmail.com, \\ ${ }^{3}$ mahadirsoleh1626@gmail.com
}

\begin{abstract}
In a company, salary is a salary for employees who have been working for a month. However, in order to provide fair salary to all employees, the company must determine the criteria for providing salary. By using fuzzy logic, wages can be determined by going through the following stages: Fuzzification, Formation of the knowledge base, Fuzzy Inference, and Defuzzification. One of the fuzzy logic methods that can be used is the Tsukamoto method, where this method has an output in the form of firm values. To determine the salary, the data is collected from the Central Statistics Agency website in accordance with the criteria to be examined. With this research, employers can use the calculations from this research to determine salary salaries for their employees quickly, well, and precisely. So that the problem of determining the wages of their employees' salaries can be resolved properly.
\end{abstract}

Keywords: Fuzzy Logic, Tsukamoto Inference, Salary Wages, Companies

\begin{abstract}
Abstrak
Dalam perusahaan, upah gaji merupakan bayaran untuk para karyawan yang telah mengerjakan pekerjaannya selama sebulan. Namun, untuk memberikan upah gaji yang adil kepada seluruh karyawan, pihak perusahaan haruslah menentukan kriteria-kriteria dalam pemberian upah gaji. Dengan menggunakan logika fuzzy, maka upah gaji dapat ditentukan dengan melalui tahapan-tahapan sebagai berikut: Fuzzifikasi, Pembentukan basis pengetahuan, Inferensi fuzzy, dan Defuzzifikasi. Salah satu metode logika fuzzy yang dapat digunakan adalah metode Tsukamoto, dimana metode ini memiliki ouput yang berbentuk nilai tegas. Untuk menentukan upah gaji tersebut, maka dilakukan pengambilan data dari situs Badan Pusat Statistik yang sesuai dengan kriteria yang akan diteliti. Dengan adanya penelitian ini, maka para pengusaha dapat menggunakan perhitungan dari penelitian ini untuk menentukan upah gaji pada karyawan mereka dengan cepat, baik, dan tepat. Sehingga masalah penentuan upah gaji karyawan mereka dapat teratasi dengan baik.
\end{abstract}

Kata Kunci: Fuzzy Logic, Inferensi Tsukamoto, Upah Gaji, Perusahaan

\section{Pendahuluan}

Dalam perusahaan, upah gaji merupakan bayaran untuk para karyawan yang telah mengerjakan pekerjaannya selama sebulan. Namun, untuk memberikan upah gaji yang adil kepada seluruh karyawan, pihak perusahaan haruslah menentukan kriteriakriteria dalam pemberian upah gaji. Kriteria-kriteria yang dapat digunakan adalah tingkat pendidikan karyawan dan jumlah jam kerja karyawan selama seminggu. Meskipun begitu, untuk menentukannya akan memerlukan perhitungan yang tepat agar akurat. Dengan perkembangan teknologi yang sangat pesat, banyak hal yang dulunya dilakukan secara manual dapat dilakukan secara otomatis dengan penggunaan teknologi. Salah satunya adalah dalam hal pengambilan keputusan, sehingga sebuah keputusan dapat diambil dengan tepat berdasarkan inputan argumen (kriteria). Salah satu metode dalam pengambilan keputusan adalah menggunakan 
logika fuzzy, karena dapat menentukan sebuah nilai berdasarkan kriteria yang memiliki nilai samar-samar seperti halnya masalah yang dibahas pada penelitian ini. Metode dari logika fuzzy yang digunakan adalah metode Tsukamoto, karena metode ini memiliki ouput berbentuk nilai tegas. Tujuan dari penelitian ini adalah menerapkan logika fuzzy untuk menentukan upah gaji karyawan per bulan berdasarkan tingkat pendidikan dan jumlah jam kerja, agar upah gaji tersebut dapat diberikan secara adil dan sesuai. Sehingga para pengusaha dapat menggunakan perhitungan dari penelitian ini untuk menentukan upah gaji pada karyawan mereka dengan cepat, baik, dan tepat sesuai dengan pendidikan terakhir dan jumlah jam kerja mereka, sehingga nantinya pengusaha tersebut tidak mengalami kerugian akibat tidak memberikan upah dengan adil dan sesuai.

\section{Metodologi Penelitian}

Logika merupakan ilmu yang mempelajari secara sistematis kaidah-kaidah penalaran yang absah (valid). Ada dua jenis logika yang ada pada kehidupan manusia, yaitu logika crisp (tegas) dan logika fuzzy (samar-samar). Logika tegas hanya memiliki dua buah keadaan pada setiap pernyataan, yaitu true (1) dan false (0). Sedangkan, logika fuzzy memiliki nilai yang samar-samar diantara 0 dan 1 [1].

Fuzzy Inferensi Tsukamoto atau logika fuzzy ini didasarkan pada teori himpunan fuzzy yang berbentuk IF-THEN untuk mengambil keputusan dalam bentuk nilai tegas dari nilai samar-samar. Fuzzy Inferensi Tsukamoto ini menggunakan fungsi keanggotaan yang berasal dari data yang diinput untuk dapat menentukan nilai tegas [2]. Kelebihan Fuzzy Inferensi Tsukamoto, antara lain: 1) Fuzzy Inferensi Tsukamoto memodelkan perasaan atau intuisi dengan cara merubah nilai crisp menjadi nilai linguistik dengan fuzzification dan kemudian memasukkannya ke dalam rule yang dibuat berdasarkan knowledge. 2) Fuzzy Inferensi Tsukamoto cocok digunakan pada sebagian besar permasalahan yang terjadi di dunia nyata. Permasalahan di dunia nyata kebanyakan bukan biner dan bersifat non linier sehingga Fuzzy Inferensi Tsukamoto cocok digunakan karena menggunakan nilai linguistik yang tidak linier [3].

Data yang digunakan pada penelitian ini diambil dari situs web Badan Pusat Statistik, dan kemudian mengubah data-data tersebut menjadi sebuah himpunan agar dapat digunakan untuk menentukan nilai tegas pada penelitian ini. Data tersebut merupakan data upah gaji berdasarkan tingkat pendidikan dan jumlah jam kerja di Indonesia pada bulan Februari dan Agustus tahun 2019 [4].

\section{Hasil dan Pembahasan}

Tahap awal yang akan dilakukan pada penelitian ini adalah tahap fuzzifikasi data agar data yang akan diolah dapat dihitung berdasarkan nilai keanggotaannya.

\subsection{Fuzzifikasi}

Pada tahap ini, setiap variabel akan ditentukan fungsi keanggotaannya. Dalam setiap fungsi keanggotaan, terdapat aturan untuk menentukan nilai fuzzy-nya. Berikut ini adalah fungsi keanggotaan dari variabel yang digunakan dalam penelitian ini [5-7].

a. Fungsi keanggotaan dari variabel Tingkat Pendidikan

Variabel ini disusun berdasarkan tingkatan pendidikan dan lama waktu untuk menyelesaikan pendidikan hingga ke tingkat tersebut (dalam tahun). Dalam variabel ini, terdapat empat tingkatan mulai dari Sekolah Dasar (SD) dengan lama pendidikan sekitar 1-7 tahun, Sekolah Menengah Pertama (SMP) dengan lama pendidikan 6-10 tahun (karena sebelumnya sudah melalui SD), Sekolah Menengah Atas (SMA) dengan lama pendidiakan 9-13 tahun, dan Sekolah Tinggi/Perguruan Tinggi (ST) dengan lama pendidikan 12 tahun ke atas. 


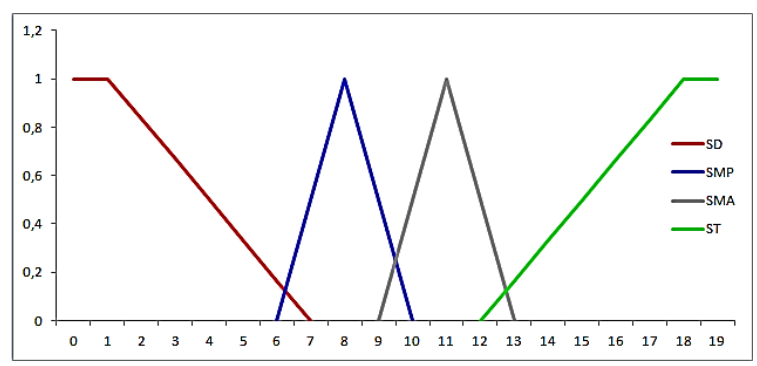

Gambar 1. Model keanggotaan fuzzy pada variabel tingkat pendidikan

$$
\begin{gathered}
\mu_{S D}=\left\{\begin{array}{ccc}
0 ; & x>7 \\
\frac{(7-x)}{(7-1)} ; & 1 \leq x \leq 7 \\
1 ; & x<1
\end{array}\right. \\
\mu_{S M P}=\left\{\begin{array}{ccc}
0 ; & x<9 \\
\frac{(x-6)}{(8-6)} ; & 6 \leq x \leq 8 \\
1 ; & x=8 \\
\frac{(10-x)}{(10-8)} ; & 8 \leq x \leq 10 \\
0 ; & x>10
\end{array}\right.
\end{gathered}
$$

\section{b. Fungsi keanggotaan dari variabel Lama Waktu Kerja dalam Seminggu}

Variabel ini didasarkan pada jumlah jam kerja dalam waktu seminggu, dimana ada 3 buah keanggotaan yang terdiri dari jam kerja singkat, jam kerja sedang, dan jam kerja panjang (lama).

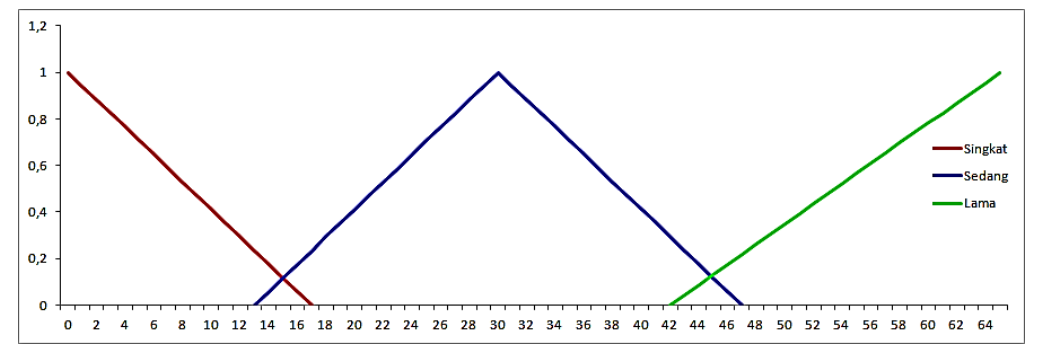

Gambar 2. Model keanggotaan fuzzy pada variabel lama waktu kerja

$$
\begin{gathered}
=\left\{\begin{array}{ccc}
0 ; & x>17 \\
\frac{(17-x)}{(17-0)} ; & 0 \leq x \leq 17 \\
1 ; & x<0
\end{array} \quad \mu_{\text {Sedang }}=\left\{\begin{array}{cc}
0 ; & x<13 \\
\frac{(x-13)}{(30-13)} ; & 13 \leq x \leq 30 \\
1 ; & x=30 \\
\frac{(47-x)}{(47-30)} ; & 30 \leq x \leq 47 \\
0 ; & x>47
\end{array}\right.\right. \\
\mu_{\text {Lama }}=\left\{\begin{array}{cc}
0 ; & x<42 \\
\frac{(65-x)}{(65-42)} ; & 42 \leq x \leq 65 \\
1 ; & x>65
\end{array}\right.
\end{gathered}
$$

\section{c. Fungsi keanggotaan dari variabel Upah Gaji}

Di variabel ini terdapat 3 buah keanggotaan, yaitu upah sedikit, upah sedang, upah banyak. Untuk mempermudah perhitungan, setiap upah yang ditampilkan pada 
penelitian ini berbentuk puluhan dan satuan saja, dimana sebenarnya upah tersebut berbentuk jutaan dan ratus ribuan. Upah tersebut dikonversi menjadi puluhan dan satuan dengan membagi upah yang sebenarnya dengan 100000 (seratus ribu).

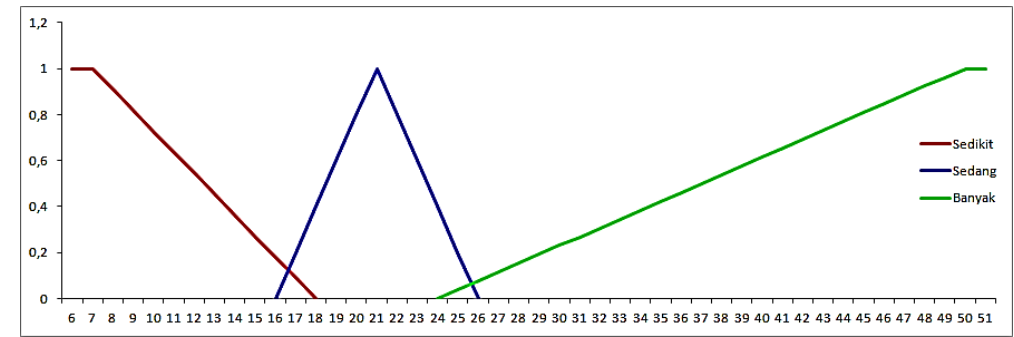

Gambar 3. Model keanggotaan fuzzy pada variabel upah gaji

\subsection{Pembentukan Basis Pengetahuan Fuzzy (Rules)}

Setelah tahap penentuan fungsi keanggotaan selesai, maka selanjutnya adalah menentukan aturan-aturan (rules) yang akan digunakan pada proses inferensi. Aturan yang digunakan adalah sebagai berikut:

$\begin{array}{ll}{[R 1]} & \text { Jika Tkt. Pend. }=\text { SD } \\ {[R 2]} & \text { Jika Tkt. Pend. }=\text { SD } \\ {[R 3]} & \text { Jika Tkt. Pend. }=\text { SD } \\ {[R 4]} & \text { Jika Tkt. Pend. }=\text { SMP } \\ {[R 5]} & \text { Jika Tkt. Pend. }=\text { SMP } \\ {[R 6]} & \text { Jika Tkt. Pend. }=\text { SMP } \\ {[R 7]} & \text { Jika Tkt. Pend. }=\text { SMA } \\ {[R 8]} & \text { Jika Tkt. Pend. }=\text { SMA } \\ {[R 9]} & \text { Jika Tkt. Pend. = SMA } \\ {[R 10]} & \text { Jika Tkt. Pend. }=\text { ST } \\ {[R 11]} & \text { Jika Tkt. Pend. }=\text { ST } \\ {[R 12]} & \text { Jika Tkt. Pend. }=\text { ST }\end{array}$

[R1] Jika Tkt. Pend. = SD

[R2] Jika Tkt. Pend. $=$ SD

[R3] Jika Tkt. Pend. = SD

[R4] Jika Tkt. Pend. = SMP

[R6] Jika Tkt. Pend. $=$ SMP

[R7] Jika Tkt. Pend. = SMA

[R8] Jika Tkt. Pend. = SMA

[R10] Jika Tkt. Pend. $=$ ST

[R12] Jika Tkt. Pend. $=$ ST

\begin{abstract}
Dan Lama Kerja $=$ Singkat Maka Upah Gaji $=$ Sedikit Dan Lama Kerja $=$ Sedang Maka Upah Gaji $=$ Sedikit Dan Lama Kerja = Lama Maka Upah Gaji = Sedang Dan Lama Kerja $=$ Singkat Maka Upah Gaji $=$ Sedikit Dan Lama Kerja $=$ Sedang Maka Upah Gaji $=$ Sedikit Dan Lama Kerja = Lama Maka Upah Gaji = Sedang Dan Lama Kerja = Singkat Maka Upah Gaji = Sedikit Dan Lama Kerja $=$ Sedang Maka Upah Gaji $=$ Sedang Dan Lama Kerja = Lama Maka Upah Gaji $=$ Banyak Dan Lama Kerja $=$ Singkat Maka Upah Gaji $=$ Sedang Dan Lama Kerja $=$ Sedang Maka Upah Gaji $=$ Banyak Dan Lama Kerja $=$ Lama Maka Upah Gaji $=$ Banyak
\end{abstract}

\subsection{Inferensi Fuzzy}

Pada penelitian ini, masalah yang akan diselesaikan adalah upah gaji untuk karyawan jika ia merupakan lulusan SMA (12 tahun belajar dari SD) dan memiliki pekerjaan dengan jumlah jam kerja seminggu adalah 32 jam. Lalu, nilai pada masalah tersebut akan dihitung nilai keanggotaannya berdasarkan aturan fungsi keanggotaan yang telah ditentukan sebelumnya, sehingga diperoleh perhitungan sebagai berikut:

a) Perhitungan fungsi keanggotaan variabel tingkat pendidikan:

$$
\begin{array}{ll}
\mu_{S D}=12>6=0 & \mu_{S M A}=\frac{13-12}{13-11}=0,5 \\
\mu_{S M P}=12>9=0 & \mu_{S T}=\frac{12-12}{18-12}=0
\end{array}
$$

b) Perhitungan fungsi keanggotaan variabel jumlah jam kerja:

$$
\begin{aligned}
& \mu_{\text {Singkat }}=32>18=0 \\
& \mu_{\text {Sedang }}=\frac{47-32}{47-30}=0,882353 \\
& \mu_{\text {Lama }}=32<42=0
\end{aligned}
$$

Lalu, aturan untuk perhitungan fuzzy-nya dapat diaplikasikan dengan menggunakan nilai keanggotaan yang telah didapat sebelumnya. Proses perhitungan fuzzy pada masalah tersebut dapat dilihat seperti dibawah:

[R1] Jika Tkt. Pend = SD Dan Jam Kerja = Singkat Maka Upah Gaji = Sedikit

$$
\begin{aligned}
& \alpha_{\text {predikat }(1)}=\operatorname{MIN}\left(\mu_{S D}[12] ; \mu_{\text {Singkat }}[32]\right)=\operatorname{MIN}(0 ; 0)=0 \\
& z_{1}=\frac{b-x}{b-a}=\frac{18-x}{18-7}
\end{aligned}
$$




$$
\begin{aligned}
& 0=\frac{18-x}{11} \\
& 18-x=11 * 0 \\
& -x=0-18=-18 \\
& x=18
\end{aligned}
$$

[R2] Jika Tkt. Pend = SD Dan Jam Kerja $=$ Sedang Maka Upah Gaji $=$ Sedikit

$$
\begin{aligned}
& \alpha_{\text {predikat }(2)}=\operatorname{MIN}\left(\mu_{S D}[12] ; \mu_{\text {Sedang }}[32]\right)=\operatorname{MIN}(0 ; 0,8823)=0 \\
& Z_{2}=\frac{b-x}{b-a}=\frac{18-x}{18-7} \\
& 0=\frac{18-x}{11} \\
& 18-x=11 * 0 \\
& -x=0-18=-18 \\
& \quad x=18
\end{aligned}
$$

Perhitungan tersebut dilakukan pada semua aturan untuk menghitung upah gaji dari masalah yang diteliti. Hasil yang diperoleh dari aturan-aturan tersebut adalah sebagai berikut:

Tabel 1. Hasil perhitungan inferensi Tsukamoto

\begin{tabular}{|l|c|l|}
\hline Rule & $\alpha_{\text {predikat }}$ & $\mathrm{Z}$ \\
\hline R1 & 0 & 18 \\
\hline R2 & 0 & 18 \\
\hline R3 & 0 & 16 \\
\hline R4 & 0 & 18 \\
\hline R5 & 0 & 18 \\
\hline R6 & 0 & 16 \\
\hline
\end{tabular}

\begin{tabular}{|l|c|l|}
\hline Rule & $\alpha_{\text {predikat }}$ & $\mathrm{Z}$ \\
\hline R7 & 0 & 18 \\
\hline R8 & 0,5 & 18,5 \\
\hline R9 & 0 & 24 \\
\hline R10 & 0 & 16 \\
\hline R11 & 0 & 24 \\
\hline R12 & 0 & 24 \\
\hline
\end{tabular}

\subsection{Defuzzifikasi}

Setelah hasil inferensi didapat, lalu tahap defuzzifikasi dilakukan. Disini, hasil tadi akan dihitung dengan persamaan berikut:

$Z=\frac{\sum\left(\alpha_{\text {predikat }(\mathrm{n})} * \mathrm{Z}_{\mathrm{n}}\right)}{\alpha_{\text {predikat }(n)}}$

berikut adalah persamaannya setelah nilai-nilai inferensi tadi dimasukkan:

$$
Z=
$$

$\frac{(0 * 18)+(0 * 18)+(0 * 16)+(0 * 18)+(0 * 18)+(0 * 16)+(0 * 18)+(0,5 * 18,5)+(0 * 24)+(0 * 16)+(0 * 24)+(0 * 24)}{0+0+0+0+0+0+0+0,5+0+0+0+0}$

$$
Z=\frac{9,25}{0,5}=18,5
$$

Karena nilai upah diubah menjadi puluhan dengan membaginya dengan 100.000, maka upah yang didapat melalui perhitungan ini harus dikalikan dengan 100.000 lagi. Sehingga, upah perbulan yang sesuai dengan karyawan yang memiliki tingkat pendidikan terakhir SMA dan bekerja dengan jumlah jam kerja 32 jam per minggu adalah Rp. 1.850.000.

\section{Kesimpulan}

Untuk menyelesaikan masalah yang memiliki nilai samar-samar seperti kasus ini, logika fuzzy dapat digunakan dengan baik sehingga hasil dapat diperoleh dengan jelas. Dan dengan adanya penelitian ini, diharapkan dapat digunakan oleh perusahaanperusahaan yang ingin memberikan karyawan mereka upah gaji perbulan berdasarkan tingkat pendidikan dan lama waktu kerja dalam seminggu

\section{Daftar Pustaka}

[1] M. Ula, "Implementasi Logika Fuzzy Dalam Optimasi Jumlah Pengadaan Barang Menggunakan Metode Tsukamoto (Studi Kasus : Toko Kain My Text)," Jurnal ECOTIPE, vol. 1, no. 2, pp. 36-46, 2014. 
[2] M. Arizal, N. Dengen dan Islamiyah, "Aplikasi Logika Fuzzy Dalam Optimisasi Stok Bahan Menggunakan Metode Tsukamoto," Prosiding Seminar Ilmu Komputer dan Teknologi Informasi, pp. 86-90, 2017.

[3] D. Mahendra, "Implementasi Fuzzy Inference System Tsukamoto Untuk Penentuan Topik Tugas Ahir," Jurnal SIMETRIS, vol. 7, no. 1, pp. 337-344, 2016.

[4] I. S. Damanik, A. P. Windarto, A. Wanto, Poningsih, S. R. Andani, and W. Saputra, "Decision Tree Optimization in C4.5 Algorithm Using Genetic Algorithm," Journal of Physics: Conference Series, vol. 1255, no. 1, pp. 1-7, 2019.

[5] H. Siahaan, H. Mawengkang, S. Efendi, A. Wanto, and A. Perdana Windarto, "Application of Classification Method C4.5 on Selection of Exemplary Teachers," Journal of Physics: Conference Series, vol. 1235, no. 1, 2019.

[6] D. Hartama, A. Perdana Windarto, and A. Wanto, "The Application of Data Mining in Determining Patterns of Interest of High School Graduates," Journal of Physics: Conference Series, vol. 1339, no. 1, pp. 1-6, 2019.

[7] M. Widyastuti, A. G. Fepdiani Simanjuntak, D. Hartama, A. P. Windarto, and A. Wanto, "Classification Model C.45 on Determining the Quality of Custumer Service in Bank BTN Pematangsiantar Branch," Journal of Physics: Conference Series, vol. 1255, no. 012002, pp. 1-6, 2019. 